\title{
Cartilaginous features in matrix-producing carcinoma of the breast: four cases report with histochemical and immunohistochemical analysis of matrix molecules
}

\author{
Kimihide Kusafuka ${ }^{1}$, Koji Muramatsu ${ }^{1,2}$, Masako Kasami ${ }^{1}$, Ken Kuriki ${ }^{3}$, Kumiko Hirobe ${ }^{1}$, \\ Isamu Hayashi ${ }^{1}$, Hideto Watanabe ${ }^{4}$, Yuji Hiraki ${ }^{5}$, Chisa Shukunami ${ }^{5}$, Toru Mochizuki ${ }^{2}$ \\ and Toru Kameya ${ }^{1}$
}

${ }^{1}$ Pathology Division, Shizuoka Cancer Center Hospital and Research Institute, Nagaizumi-cho, Sunto-gun, Shizuoka, Japan; ${ }^{2}$ Cancer Diagnostics Research Division, Shizuoka Cancer Center Hospital and Research Institute, Nagaizumi-cho, Sunto-gun, Shizuoka, Japan; ${ }^{3}$ Division of Pathology, Yaizu City Hospital, Yaizu, Shizuoka, Japan; ${ }^{4}$ Institute for Molecular Science of Medicine, Aichi Medical University, Nagakute-cho, Aichi-gun, Aichi, Japan and ${ }^{5}$ Department of Molecular Interaction and Tissue Engineering, Institute for Frontier Sciences, Sakyo-ku, Kyoto, Japan

\begin{abstract}
Matrix-producing carcinoma of the breast is a well-established entity in the group of metaplastic carcinoma, which is histologically characterized by myxochondroid matrix formation and is extremely rare. We describe here four additional cases of matrix-producing carcinoma of the breast. All cases of matrix-producing carcinoma show nest-like, sheet-like, and cord-like growth of tumor cells with cellular atypia, in addition to scattered cancer cells within myxoid or myxohyalinous stroma. Three of four cases showed an acellular or oligocellular matrix-rich zone in the center of the tumor. Immunohistochemically, cancer cells of all cases were positive for cytokeratins and epithelial membrane antigens and partially positive for sox9 and p63. Aggrecan and type II collagen, which are cartilage-specific matrix molecules, were deposited in the stroma of all cases. Type I and type IV collagens were also deposited on the stroma of all cases. These findings suggest that, although cancer cells of matrix-producing carcinoma of the breast are epithelial, they transdifferentiate to chondrocyte-like cells and produce cartilage-specific matrix molecules, which are useful markers for diagnosing matrix-producing carcinoma.

Modern Pathology (2008) 21, 1282-1292; doi:10.1038/modpathol.2008.120; published online 11 July 2008
\end{abstract}

Keywords: aggrecan; collagens; matrix-producing carcinoma; breast; immunohistochemistry; electron-microscopy

Matrix-producing carcinoma of the breast is an extremely rare and specialized variant of metaplastic carcinoma of the breast, which is a well-established entity; ${ }^{1,2}$ because of its rarity, the features of its stroma have remained unclear.

Aggrecan is a cartilage-specific major proteoglycan. $^{3}$ This macromolecule deposits in the hypertrophic zones of growth plate cartilage, ${ }^{4}$ although it was reported to deposit in the salivary

Correspondence: Dr K Kusafuka, DDS, PhD, Pathology Division, Shizuoka Cancer Center Hospital and Research Institute, 1007 Shimonagakubo, Nagaizumi-cho, Suto-gun, Shizuoka 411-8777, Japan.

E-mail: k.kusafuka@scchr.jp

Received 21 May 2008; revised 28 May 2008; accepted 29 May 2008; published online 11 July 2008 pleomorphic adenoma, which frequently showed mesenchyme-like elements, including myxoid and chondroid tissues., ${ }^{5,6}$ Type II collagen, which is a cartilage-specific major collagen, and chondromodulin-I (ChM-I), which is cartilage-specific noncollagenous matrix protein, $, 4,7,8$ are deposited in the normal cartilaginous matrix. These molecules can be useful markers of cartilaginous differentiation. As sox9 is a transcription factor, the expression of which induces cartilaginous differentiation, ${ }^{9-11}$ this molecule is also a useful marker of chondroid differentiation in normal and neoplastic tissues. ${ }^{9-12}$

We investigated the deposition of matrix molecules in matrix-producing carcinoma of the breast, histochemically and immunohistochemically. 


\section{Materials and methods}

\section{Case Selection and Tissue Preparation}

We examined four cases that fulfilled the criteria for matrix-producing carcinoma defined by the World Health Organization Classification of Breast and Female Genital Organs ${ }^{1}$ from the pathological files of Shizuoka Cancer Center Hospital and Yaizu City Hospital, Shizuoka, Japan. Three cases were surgically resected in the Breast Surgery Division, Shizuoka Cancer Center Hospital, Shizuoka, Japan, during 2002-2007, and one case was surgically resected in Thoracic Surgery Division, Yaizu City Hospital, Shizuoka, Japan, during 2000-2007. Severalstep tissue sections were fixed in $10 \%$ formalin and processed by routine histological techniques, including periodic acid-Schiff (PAS), Alcian blue, and toluidine blue, $\mathrm{pH}$ 4.1.

\section{Immunohistochemistry}

Deparaffinized and rehydrated slides were treated with $0.1 \%$ hyaluronidase and/or $0.1 \%$ protease, or boiled in $10 \mathrm{mM}$ citrate buffer ( $\mathrm{pH} \mathrm{6.0)}$ for $10 \mathrm{~min}$ in an autoclave at $121^{\circ} \mathrm{C}$. They were then incubated with the primary antibody for $1 \mathrm{~h}$ at room temperature. The primary antibodies used in this study and their pretreatment are listed in Table 1. An EnVision (DakoCytomation, Carpinteria, CA, USA) was used for detection, employing 3,3'-diaminobendizine as the chromogen. The sections were slightly counterstained with hematoxylin. Normal breast tissue adjacent to the tumor was used as a control. The case was regarded as ' ++ ' for matrix molecules/ tumor cells, when intense and diffuse positive staining was seen in $>50 \%$ of tumor stroma/cells, whereas the case was considered to be ' + ', when $>20 \%$ of tumor stroma/cells showed strong staining. The case was considered as $\mathrm{p}+$, when positive staining was observed in 10-20\% of tumor stroma/cells, whereas $<10 \%$ of tumor stroma/cells showed ' $\mathrm{f}+$ '. The percentage of Ki-67-positive tumor cells was determined by counting $>1000$ tumor cells and was then recorded as the Ki-67 labeling index (LI).

\section{Transmission Electron Microscopy}

Small blocks, $\sim 1 \mathrm{~mm}^{3}$, of resected specimens were postfixed in $2 \%$ glutaraldehyde in $\mathrm{PBS}$ at $4{ }^{\circ} \mathrm{C}$ overnight and then for $2 \mathrm{~h}$ at $4^{\circ} \mathrm{C}$ with $1 \%$ osmium tetraoxide in PBS. They were then dehydrated in a graded series of ethanol. Following dehydration, they were transferred to propylene oxide and embedded in epoxy resin Quetol 812 (Nisshin EM, Tokyo, Japan). Ultrathin sections were cut with Ultracut (UCT, LEICA), stained with uranyl acetate and lead citrate, and observed with a JEM-1230 electron microscope (JEOL, Tokyo, Japan).

\section{Results}

\section{Clinical Data}

The prevalence of matrix-producing carcinoma was $0.2 \%$ among 1628 cases of breast cancers in our series. The clinicopathological features of matrixproducing carcinomas are summarized in Table 2. All patients were females, aged 49, 45, 47, and 64 years (mean, 51 years). Tumor size was approximately 2.1-3.2 cm. Magnetic resonance imaging and ultrasonic examination of all cases showed a ring-like appearance on T2-weighted imaging and ultrasound, which was characteristic of matrixproducing carcinoma (Figure 1). Three of four patients were treated with chemotherapy after surgery. All patients were followed up (duration of follow-up, 10 months to 3.5 years): Case 1 had right axillary lymph node metastasis at surgery and brain and lung metastases 1 year after surgery, and then died of disease. Case 2 was alive with disease and had multiple bone metastases 1 year after surgery. Cases 3 and 4 were alive with no evidence of disease 1 year and 3.5 years after surgery, respectively (Table 2).

\section{Histological Examinations}

Microscopically, all cases had predominantly circumscribed borders: in all cases, an incomplete thin fibrous band, with extension of the neoplasm into adjoining breast tissue and adipose tissue was present (Figure 2). Case 2 had only slight variation in cellular density from the periphery inward (diffuse cellularity), whereas in cases 1, 3, and 4, only the periphery of the neoplasm was densely cellular (peripheral cellularity) (Figure 3a). Although vascular invasion was not identified, case 1 showed lymphatic invasion. In all cases, the overt carcinoma showed a sheet-like, nest-like, or cord-like appearance, whereas metaplastic cells had an isolated and separate appearance within the extracellular matrix (Figure 3b). Overt carcinomas are moderately to poorly differentiated ductal carcinomas and/or ductal carcinoma in situ. Cases 1, 3, and 4 showed acellular or oligocellular hyalinous/myxohyalinous stroma in the central portions of the tumor (Figure 3c). All of the tumors had overt carcinoma contiguous with myxoid and/or myxochondroid tissue (Figure 3d and e). Although cases 1, 3, and 4 lacked an intervening spindle cell component, case 2 showed bizarre spindle cells in transitional areas (Figure 3f) where carcinoma cells appeared to be less cohesive and individual cells gradually became surrounded by matrix. Case 2 showed sarcomatoid components with overt carcinoma. In case 1, sentinel lymph node metastatic lesion showed carcinoma with small amount of myxochondroid matrix, but no metastatic lesions were obtained in other cases. Three categories of nuclear grade were almost equally distributed among all cases. Case 2 was grade 3 , whereas cases 1,3 , and 4 were grade 2 . 
Table 1 Antibodies used in this immunohistochemical examination.

\begin{tabular}{|c|c|c|c|c|}
\hline Antibody (antigen) & $P / M$ & Clone & Antigen retrieval & Source \\
\hline pan-CK & $\mathrm{M}$ & $\mathrm{AE}-1 / 3$ & Autoclave $^{\mathrm{a}}$ & Signet Laboratories, Inc. (Dedham, MA, USA) \\
\hline EMA & $\mathrm{M}$ & E9 & & DakoCytomation (Carpinteria, CA, USA) \\
\hline HMWK & $\mathrm{M}$ & $34 \beta \mathrm{E} 12$ & Autoclave $^{\mathrm{a}}$ & DakoCytomation \\
\hline CK7,8 & $\mathrm{M}$ & CAM5.2 & Autoclave $^{\mathrm{a}}$ & Beckton Dickinson (San Jose, CA, USA) \\
\hline CK19 & $\mathrm{M}$ & Ks19.1 & Autoclave $^{\mathrm{a}}$ & Progen Bioteknik (Heidelberg, Germany) \\
\hline CK7 & $\mathrm{M}$ & OV-TL12/30 & Autoclave $^{\mathrm{a}}$ & DakoCytomation \\
\hline CK5/6 & $\mathrm{M}$ & D5/16B4 & Autoclave $^{\mathrm{a}}$ & DakoCytomation \\
\hline p63 & $\mathrm{M}$ & $4 \mathrm{~A} 4$ & Autoclave $^{\mathrm{a}}$ & $\mathrm{LAB}$ vision \\
\hline ASMA & $\mathrm{M}$ & 1A4 & Autoclave $^{\mathrm{a}}$ & DakoCytomation \\
\hline Calponin & $\mathrm{M}$ & CALP & & DakoCytomation \\
\hline GFAP & $\mathrm{P}$ & & Autoclave $^{\mathrm{a}}$ & DakoCytomation \\
\hline S-100 protein & $\mathrm{P}$ & & & DakoCytomation \\
\hline Vimentin & $\mathrm{M}$ & V9 & Autoclave $^{\mathrm{a}}$ & DakoCytomation \\
\hline ER & $\mathrm{M}$ & 1D5 & Autoclave $^{\mathrm{a}}$ & DakoCytomation \\
\hline PgR & $\mathrm{M}$ & PgR636 & Autoclave $^{\mathrm{a}}$ & DakoCytomation \\
\hline Her-2 & $\mathrm{P}$ & & Autoclave $^{\mathrm{a}}$ & DakoCytomation \\
\hline CD99 (MIC2) & $\mathrm{M}$ & $\mathrm{O} 13$ & Autoclave $^{\mathrm{a}}$ & Signet Laboratories Inc. \\
\hline sox 9 & $\mathrm{P}$ & & Autoclave $^{\mathrm{b}}$ & $\begin{array}{l}\text { Santa Cruz Biotechnology Inc. } \\
\text { (Santa Cruz, CA, USA) }\end{array}$ \\
\hline Type II collagen & $\mathrm{M}$ & II-4C11 & Pepsin & Daiichi Fine Chemical (Toyama, Japan) \\
\hline Aggrecan & $\mathrm{P}$ & & Hyal+protease & Local \\
\hline ChM-I & $\mathrm{P}$ & & Protease & Local \\
\hline Type I collagen & $\mathrm{M}$ & $\mathrm{I}-8 \mathrm{H} 5$ & Protease & Daiichi Fine Chemical \\
\hline Type III collagen & $\mathrm{M}$ & III-53 & & Daiichi Fine Chemical \\
\hline Type IV collagen & $\mathrm{M}$ & IV-4H12 & Protease & Daiichi Fine Chemical \\
\hline Ki-67 & $\mathrm{M}$ & MIB-1 & Autoclave $^{\mathrm{a}}$ & DakoCytomation \\
\hline
\end{tabular}

ASMA, alpha-smooth muscle actin; ChM-I, chondromodulin-I; CK, cytokeratin; EMA, epithelial membrane antigen; ER, estrogen receptor; GFAP, glial fibrillary acidic protein; HMWK, high-molecular-weight keratin; M, monoclonal antibody; P, polyclonal antibody; PgR, progesterone receptor.

${ }^{\mathrm{a}}$ Autoclave in $0.1 \mathrm{mmol} / \mathrm{l}$ citrate buffer, $\mathrm{pH}$ 6.0.

${ }^{\mathrm{b}}$ Autoclave in TE buffer (DakoCytomation: S2367), $\mathrm{pH}$ 9.0; pepsin, $0.4 \%$ pepsin in $0.01 \mathrm{~mol} / \mathrm{l} \mathrm{HCl}$, at $37^{\circ} \mathrm{C}, 45$ min; hyal, $0.02 \%$ hyaluronidase in acetate buffer, pH 5.0 at $37^{\circ} \mathrm{C}, 45 \mathrm{~min}$; protease, $0.05 \%$ protease (Sigma: P-8038) in Tris-HCl, $\mathrm{pH} 7.4$ at $37^{\circ} \mathrm{C}, 45 \mathrm{~min}$.

Table 2 Clinicopathological data.

\begin{tabular}{|c|c|c|c|c|}
\hline & Case 1 & Case 2 & Case 3 & Case 4 \\
\hline Age (years) & 49 & 45 & 47 & 64 \\
\hline Gender & Female & Female & Female & Female \\
\hline Size & $21 \times 20 \times 19 \mathrm{~mm}$ & $21 \times 15 \times 18 \mathrm{~mm}$ & $21 \times 19 \times 19 \mathrm{~mm}$ & $32 \times 24 \times 25 \mathrm{~mm}$ \\
\hline Site & rt C & rt D & rt $\mathrm{AB}$ & rt E \\
\hline $\mathrm{f}$ & + & + & + & + \\
\hline $\mathrm{s}$ & - & - & - & - \\
\hline $\mathrm{v}$ & - & + & - & + \\
\hline ly & + & - & - & - \\
\hline $\mathrm{pN}$ & $1 / 11$ & $0 / 2$ & $0 / 3$ & ND \\
\hline postOPE CRT & $\mathrm{CT} \rightarrow \mathrm{RT}+\mathrm{CT}$ & CT & $\mathrm{CT}+\mathrm{RT}$ & RT \\
\hline Prognosis & DOD (3 years: Br, Lu) & AWD (1 year: Bo) & NED (10 months) & NED (3.5 years) \\
\hline
\end{tabular}

AB, inner portion; AWD, alive with disease; Bo, bone metastasis; Br, brain metastasis; C, upper lateral portion; CT, chemotherapy; D, lower lateral portion; DOD, dead of disease; E, central portion; f, fat invasion; Lu, lung metastasis; ly, lymphatic involvement; ND, not done; NED, no evidence of disease; postOPE CRT, postoperative chemoradiotherapy; rt, right; RT, radiotherapy; s, skin invasion; v, venous involvement.

Cases 1, 3, and 4 showed myxoid and myxohyalinous matrix in the central areas of the tumors, but indicated no obvious evidence of cartilaginous and/or osseous matrices (Figure 3c and d). The atypical cartilaginous component comprised the matrix component of cases 1,3 , and 4 . Case 2 showed irregularly myxohyalinous matrix interlacing cancer nests.

Histochemically, all cases had an extracellular matrix that stained metachromatically with toluidine blue, $\mathrm{pH}$ 4.1, and that revealed hyaluronidase sensitivity with Alcian blue staining. The carcinomatous cells in cases 1, 3, and 4 had PAS-positive, diastasesensitive glycogens in the cytoplasm, whereas metaplastic cells in all cases had glycogens.

\section{Immunohistochemical Examinations (Table 3)}

The pattern of immunoreactivity of overt carcinoma cells differed somewhat from that of metaplastic 


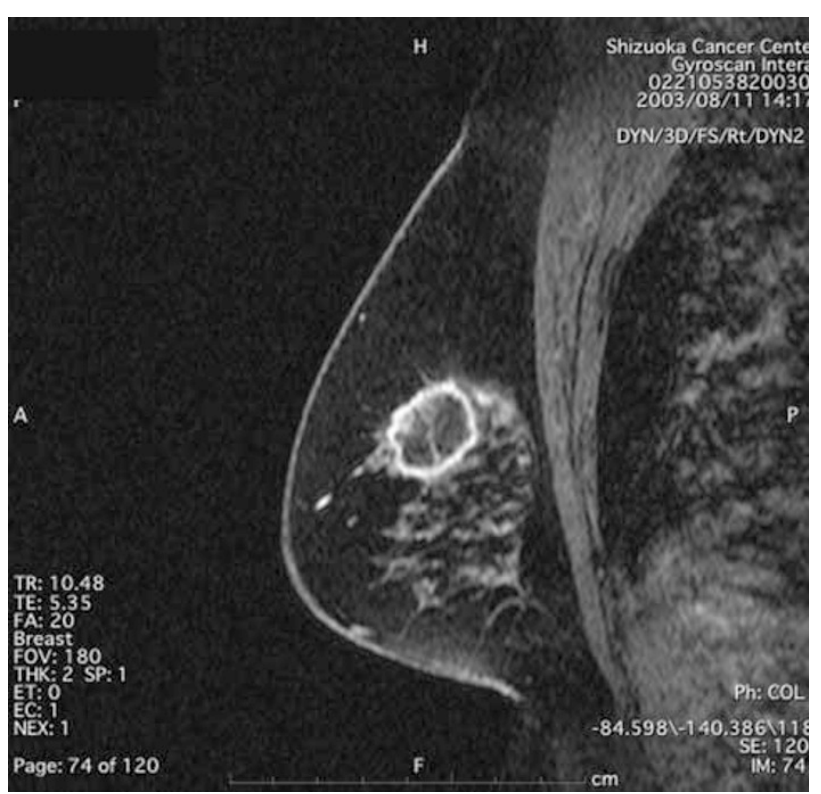

Figure 1 Magnetic resonance imaging (MRI): T2-weighted image on MRI showed ring-like enhanced appearance (case 3).

Table 3 Results of immunohistochemical analysis.

\begin{tabular}{|c|c|c|c|c|}
\hline Antibodies to & Case 1 & Case 2 & Case 3 & Case 4 \\
\hline $\mathrm{AE}-1 / 3$ & ++ & $\mathrm{p}+$ & + & ++ \\
\hline EMA & ++ & $\mathrm{p}+$ & + & ++ \\
\hline $34 \beta \mathrm{E} 12$ & + & + & $\mathrm{p}+$ & $\mathrm{p}+$ \\
\hline CAM5.2 & $\mathrm{f}_{+}$ & $\mathrm{f} \& \mathrm{w}+$ & $\mathrm{f}_{+}$ & + \\
\hline CK19 & ++ & $\mathrm{p}+$ & $\mathrm{p}+$ & + \\
\hline CK7 & $\mathrm{f}+$ & $\mathrm{f}+$ & + & ++ \\
\hline CK5/6 & ++ & + & + & $\mathrm{p}+$ \\
\hline p63 & $\mathrm{f}+$ & ++ & $\mathrm{f}+$ & $\mathrm{f}_{+}$ \\
\hline ASMA & - & - & ++ & ++ \\
\hline Calponin & - & $\mathrm{f}+$ & $\mathrm{f}+$ & $\mathrm{p}+$ \\
\hline GFAP & - & - & $\mathrm{f}_{+}$ & + \\
\hline S-100 & $f_{+}$ & ++ & + & + \\
\hline Vimentin & + & ++ & ++ & ++ \\
\hline ER & - & - & - & - \\
\hline PgR & - & - & - & - \\
\hline Her-2 & - & - & - & $\mathrm{w}+$ \\
\hline CD99 & $\mathrm{w}+$ & + & + & - \\
\hline sox9 & + & ++ & + & ++ \\
\hline Type II collagen & + & + & + & + \\
\hline Aggrecan & ++ & ++ & ++ & ++ \\
\hline ChM-I & $\mathrm{f} \& \mathrm{w}+$ & $\mathrm{f}+$ & $f \& w+$ & $\mathrm{f}_{+}$ \\
\hline Type I collagen & ++ & ++ & ++ & $\mathrm{f}+$ \\
\hline Type III collagen & $\mathrm{w}+$ & - & + & - \\
\hline Type IV collagen & + & + & ++ & + \\
\hline Ki-67 LI & $73.28 \%$ & $86.36 \%$ & $82.49 \%$ & $76.32 \%$ \\
\hline
\end{tabular}

ASMA, alpha-smooth muscle actin; ChM-I, chondromodulin-I; CK, cytokeratin; EMA, epithelial membrane antigen; ER, estrogen receptor; GFAP, glial fibrillary acidic protein; HMWK, high-molecularweight keratin; LI, labeling index; PgR, progesterone receptor.

-, negative; $\mathrm{w}+$, weakly positive; $\mathrm{f}+$, focally positive; $\mathrm{p}+$, partially positive; +, positive; ++, strongly and diffusely positive.

cells admixed with the matrix. Overt carcinoma tended to show diffuse cytokeratins (CKs), epithelial membrane antigen (EMA), and CD99 (MIC2) immunoreactivity (Figure $4 \mathrm{a}$ and $\mathrm{b}$ ), and intermediate or focal staining for glial fibrillary acidic protein,

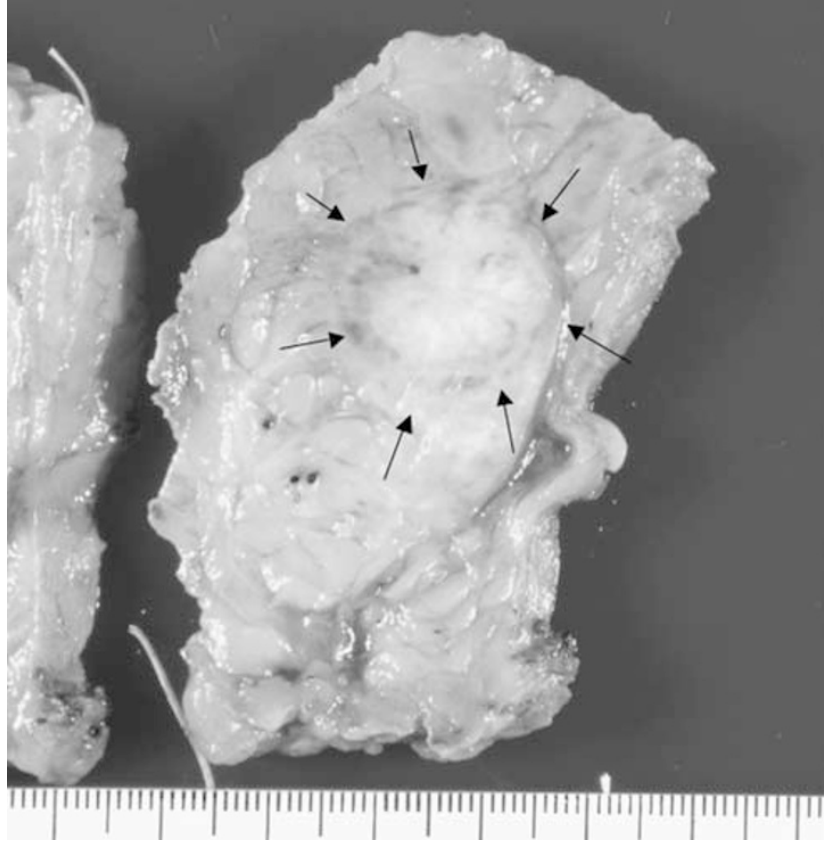

Figure 2 Macroscopic findings: on cut surface, the tumor (arrows) was a relatively well-circumscribed mass with central amorphous appearance (case 1).

alpha-smooth muscle actin, vimentin, p63, S-100 protein, and sox9 (Figure 4c-f). In contrast, metaplastic cells within the matrix had diffuse S-100 protein, vimentin, and sox9 immunoreactivity (Figure $4 \mathrm{~g}$ and $\mathrm{h}$ ), and all showed variable staining for CKs and EMA. CD99 (MIC2) was localized in the cellular membranes, whereas p63 and sox9 were in the nuclei. Alpha-smooth muscle actin and calponin were present in two (cases 3 and 4) and three cases (cases 2, 3, and 4), respectively, but all the cases lacked estrogen receptor and progesterone receptor immunoreactivity. Case 4 had strong immunoreactivity for glial fibrillary acidic protein and weak immunoreactivity for Her-2. Ki-67LIs were 73.28, 86.36, 82.49, and $76.32 \%$ in cases $1,2,3$, and 4 , respectively.

In the matrix of all cases, diffuse and strong immunoreactivity for aggrecan was observed (Figure 5a). ChM-I was only weakly and focally seen in all cases, except case 4: focal and strong immunoreactivity for ChM-I was observed among the cancer cells (Figure 5b). Stronger immunoreactivity for type II collagen was seen in the myxochondroid matrix rather than the myxoid matrix, and the pattern of type II collagen immunoreactivity was similar to that of lacunar formation in the normal cartilage and salivary pleomorphic adenomas (Figure 5c and d). Immunoreactivity for type III collagen was seen weakly in cases 2 and 3 . The acellular or oligocellular stroma of all cases indicated strong and diffuse immunoreactivity for type I collagen, whereas very weak immunoreactivity for type I collagen was seen in adjacent normal breast tissue (Figure 5e). 

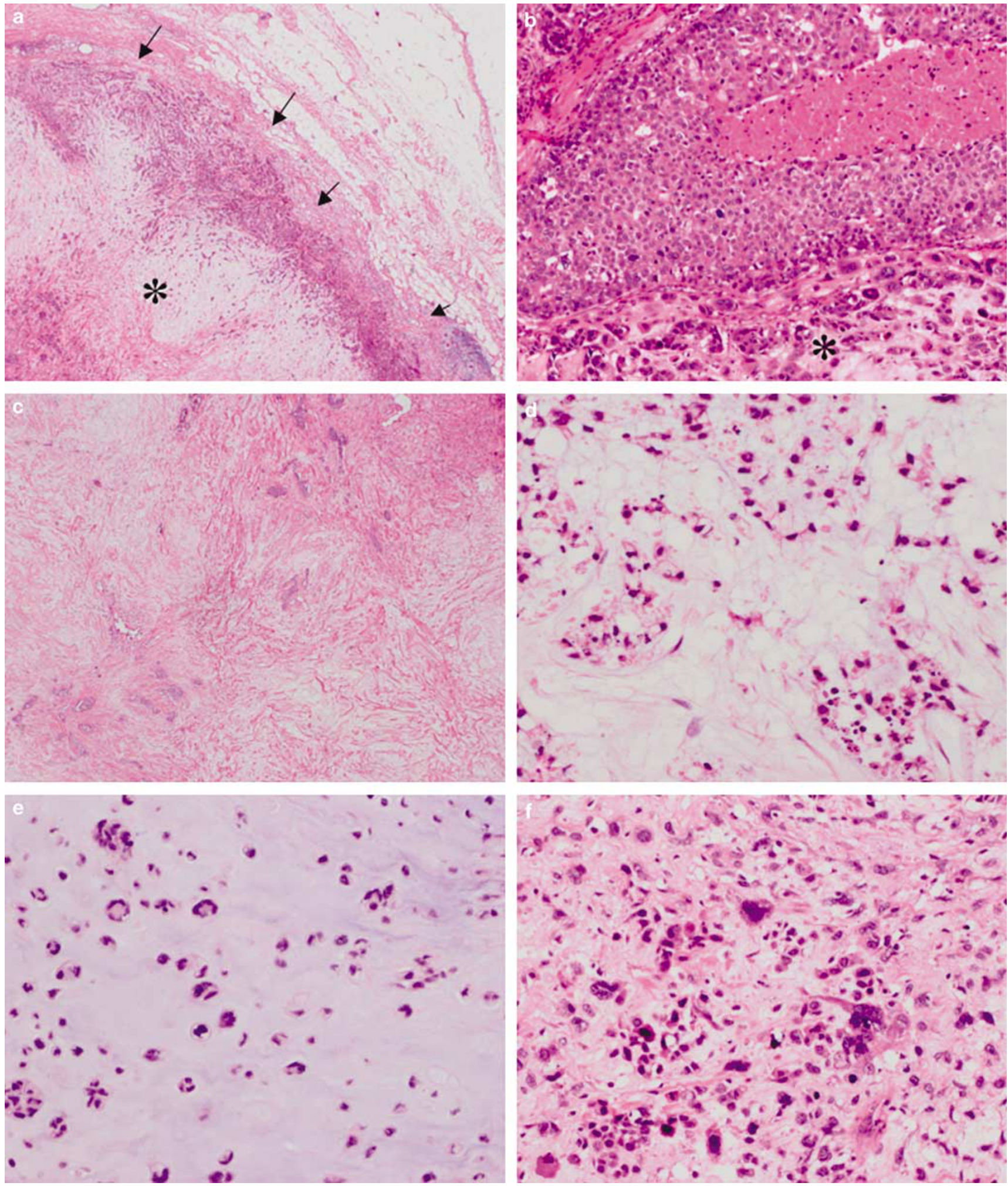

Figure 3 Microscopic findings. (a) The cancer cells (arrows) aggregated in the periphery of the tumor, whereas an acellular area (asterisks) existed in the central area (case 1). (b) The cancer cells typically showed solid carcinomatous features with cellular atypia and comedo necrosis (case 3). Note that pleomorphic and spindle-shaped metaplastic cancer cells (asterisk) were seen around the overt carcinomatous nests. (c) The central area was acellular and showed marked hyalinomyxoid stroma (case 1). (d) Myxoid stroma with cordlike metaplastic cancer cells (case 1). No obvious osseous matrix was seen in the stroma. (e) Myxoid and myxochondroid stroma within isolated metaplastic cancer cells (case 4). (f) The cancer of case 2 showed solid nests and pleomorphic cancer cells with markedly cellular atypia. The latter were sarcomatoid cells with large and bizarre hyperchromatic nuclei (case 2). 

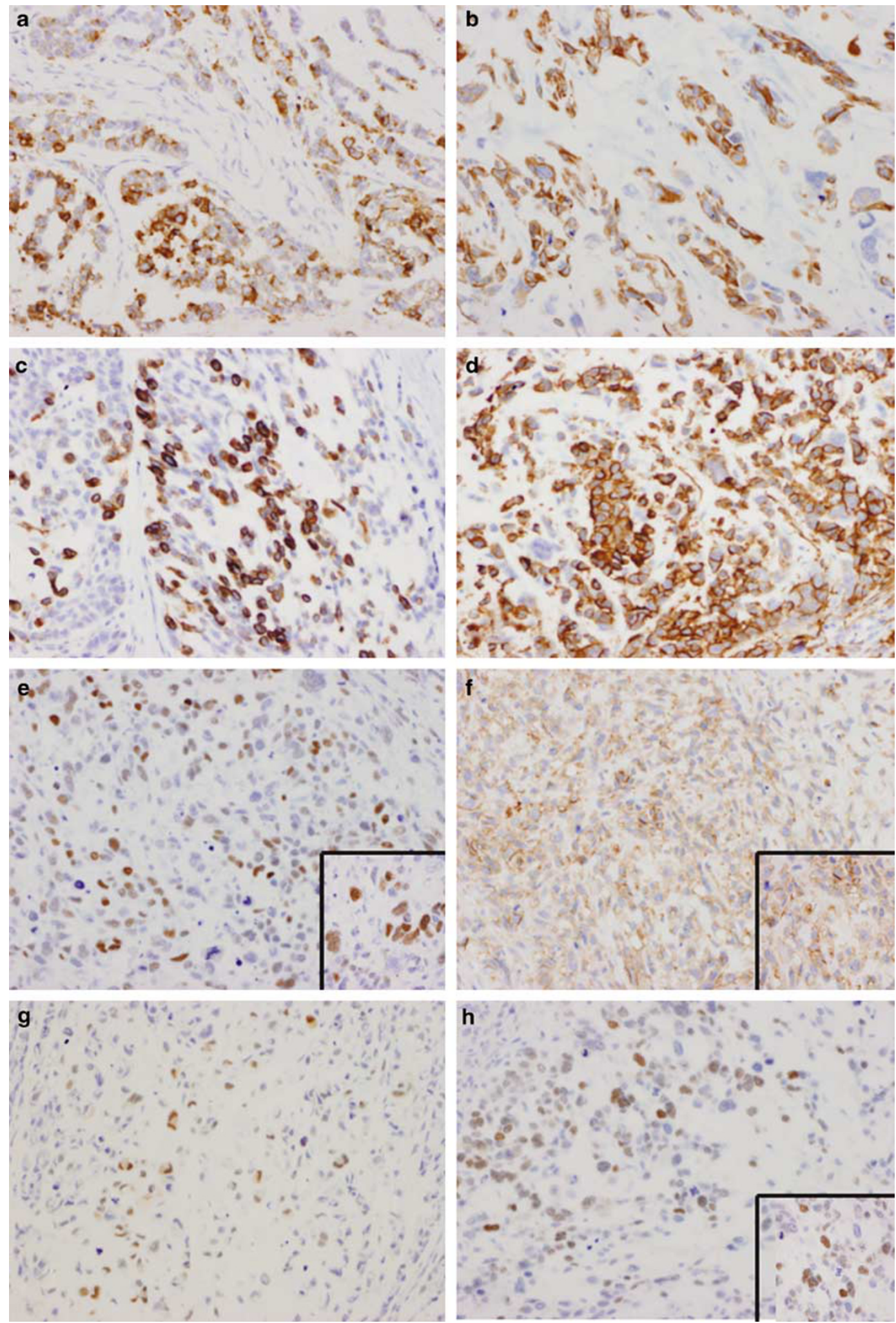

Figure 4 Immunohistochemical findings for cell differentiation markers. (a) Immunopositivity for epithelial membrane antigen was observed in cancer cells (case 1). (b) Immunopositivity for CK5/6 was seen in cancer cells (case 3). (c) Immunopositivity for glial fibrillary acidic protein was seen in cancer cells (case 4). (d) Immunopositivity for alpha-smooth muscle actin was observed in metaplastic cancer cells (case 4). (e) Immunopositivity for p63 was observed in the nuclei of metaplastic cancer cells (case 2). Inset: note the positivity in the nuclei of cancer cells. (f) Immunopositivity for CD99(MIC2) was seen in metaplastic cancer cells (case 3). Inset: note the positivity on the cellular membranes of cancer cells. (g) Immunopositivity for S-100 protein was seen in the nuclei and cytoplasm of metaplastic cancer cells (case 3). (h) Immunopositivity for sox9 was observed in the nuclei of metaplastic cancer cells (case 2). Inset: note the positivity in the nuclei of cancer cells. 

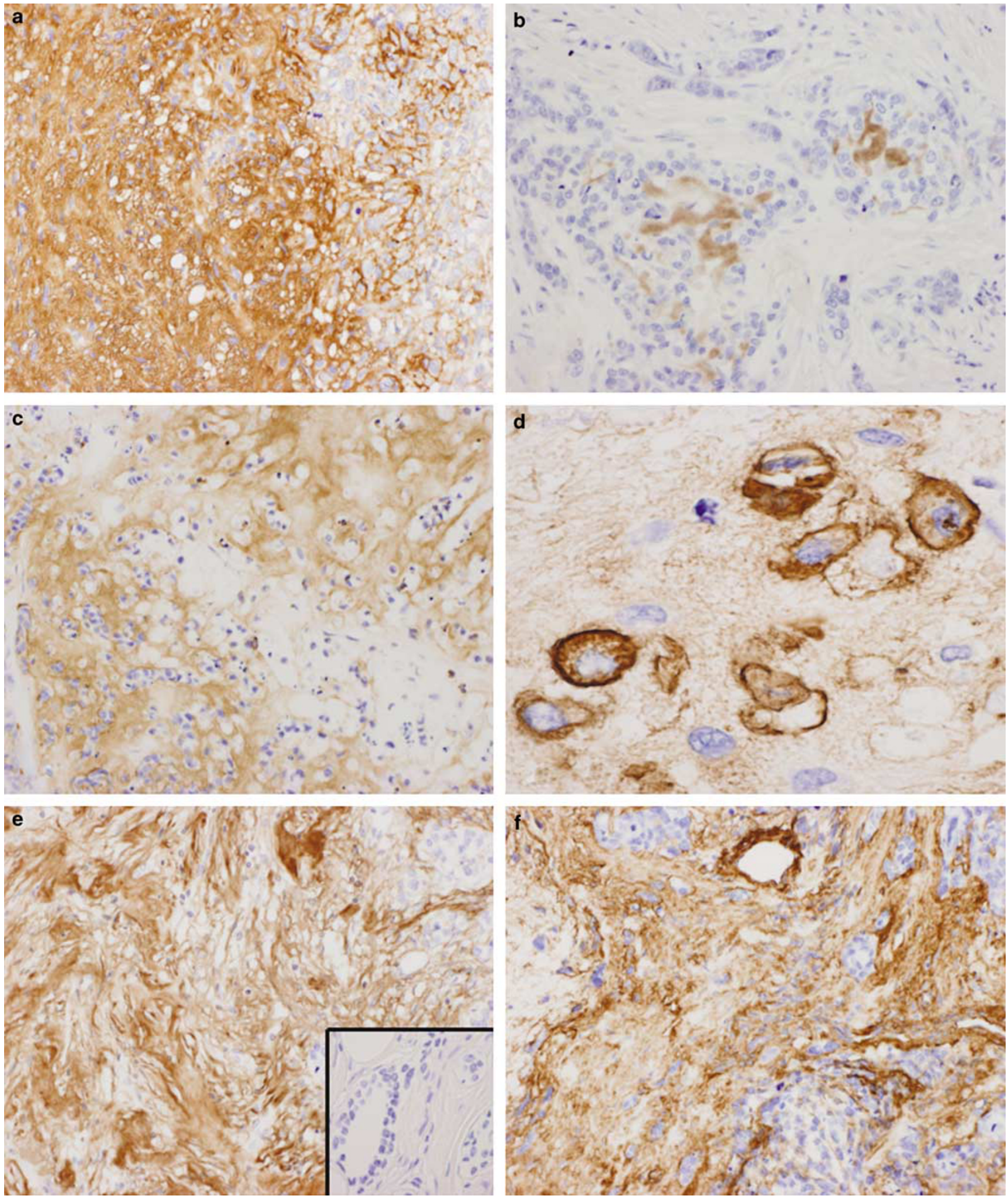

Figure 5 Immunohistochemical findings for matrix proteins. (a) Strong and diffuse immunopositivity for aggrecan was observed in hyalinous stroma of the cancer (case 3). (b) Focal and strong immunopositivity for ChM-I was seen in stroma around the cancer cells (case 4). (c) Strong and diffuse immunopositivity for type II collagen was observed around metaplastic cancer cells (case 1). (d) Strong immunopositivity for type II collagen was seen around metaplastic cells, with a ring-like pattern, which appears to be lacunar formation in cartilaginous tumors (case 2). (e) Strong and diffuse immunopositivity for type I collagen was seen in the hyalinomyxoid stroma of the cancer (case 3). Inset: note very weak immunoreactivity for type I collagen in adjacent normal breast tissue. (f) Strong and diffuse immunopositivity for type IV collagen was observed in the intercellular stroma of the breast cancer, with a fibrillar pattern (case 2). 
Immunoreactivity for type IV collagen was observed around the cancer nests with fibrillar, lining, or diffusion patterns near metaplastic areas (Figure 5f), but no immunoreactivity for type IV collagen was seen in the matrix distant to overt carcinomatous cells in all cases.

No immunoreactivity for type II and type III collagens, aggrecan, and ChM-I was seen in adjacent breast tissues. Very weak immunoreactivity for type I collagen was seen in the stroma of normal breast tissues, whereas immunoreactivity for type IV collagen was observed around the ducts and lobules in adjacent breast tissues. No immunoreactivity was seen in negative controls: replacement of the primary antibody with the normal serum and PBS.

\section{Ultrastructural Findings}

In the overt carcinoma, the cells were variably sized, cuboidal or polygonal, with desmosome-like structures at the intercellular junctions. Ductal structures with microvilli and secretory vesicles were sometimes observed in the overt carcinomatous areas. Cells were rich in organelles, and some epithelial cells possessed focally dilated segments of rough endoplasmic reticulum, actin filaments with dense patches, and tonofilaments (Figure 6a). The desmosome-like junctions were also seen between metaplastic cells (Figure 6b). The matrix composed of abundant collagen fibers, abundant proteoglycan fibrils and cores, and homogeneous, pale-staining materials (Figure 6c). Within the matrix, numerous degenerating cancer cells, such as apoptotic cells, were also seen.

\section{Discussion}

Matrix-producing carcinoma of the breast is a well-established and rare entity of metaplastic carcinoma $^{1,2}$ and was also extremely rare in our series. Characteristically, matrix-producing carcinoma shows myxoid and/or myxochondroid stroma with atypical epithelial cells. Previously, ultrastructural and immunohistochemical studies indicated that matrix-producing carcinoma had an epithelial nature: the presence of intercellular junctions such as desmosomes, tonofilaments in the cytoplasm of cancer cells, and positivity for CKs and EMA. ${ }^{2,13,14}$ Ultrastructural findings of metaplastic cells within the matrix revealed dilated segments of rough endoplasmic reticulum containing finely granular, homogeneous, pale-staining matrix materials identical to those seen in intercellular spaces. ${ }^{2}$ As immunohistochemical examination of the current cases also showed diffuse and/or focal positivity for CKs and EMA in overtly carcinomatous cells and metaplastic cells, matrix-producing carcinoma was presumed to be derived from mammary epithelial cells. In the current cases, the desmosome-like intercellular junction structures and tonofilaments in carcinomatous cells strongly support that matrixproducing carcinoma was of epithelial origin. Immunoreactivity for p63 was reported to be characteristic of metaplastic carcinoma, in which matrix-producing carcinoma is included. ${ }^{15}$ Our cases were also positive for p63. Salivary pleomorphic adenomas frequently showed the coexpression of CKs and vimentin, and moreover, neoplastic myoepithelial cells in these tumors revealed positivity for p63. ${ }^{16,17}$ Such findings supported that matrix-producing carcinoma of the breast was associated with myoepithelial cell-like differentiation: although the metaplastic cells of matrixproducing carcinoma have myoepithelial cell-like features, the origin of this cancer is considered to be derived from mammary epithelial cells. A recent report showed that CD99 (MIC2) was expressed in breast carcinoma, especially in matrix-producing carcinoma, but concluded that there was no significance between CD99 (MIC2) expression and the proliferating rate or nodal status; ${ }^{18}$ however, it was suggested that CD99 (MIC2) expression was a useful marker to differentiate metaplastic carcinomas from primary or metastatic sarcomas of the breast, although its biological significance remains unclear. As three of our cases were positive for CD99 (MIC2), histological and immunohistological findings were compatible with matrix-producing carcinoma. The high proliferating rate due to the Ki-67 labeling index in our cases may be related to CD99 (MIC2) expression in matrix-producing carcinoma.

Sox9 is a regulatory master transcription factor for differentiating chondrocytes in growth plates and skeletogenesis. ${ }^{9-11}$ Moreover, sox9 expression is an important marker for distinguishing mesenchymal chondrosarcoma from other small round cell tumors, including primitive neuroectodermal tumor/ Ewing's sarcoma, small cell osteosarcoma, small cell carcinoma, and lymphoblastic lymphoma. ${ }^{12}$ The expression of sox9 in primitive mesenchymal cells induced chondrocytic phenotype: for example, the expression of cartilage-specific matrix molecules such as type II collagen and aggrecan. ${ }^{19,20}$ In these cases, the expression of sox9 was more diffuse in the nuclei of metaplastic cells than in carcinomatous cells. S-100 protein expression in matrix-producing carcinoma, especially in metaplastic cells, is well known ${ }^{2}$ and is frequently seen in chondrocytes and chondrocytic tumors. ${ }^{21}$ Moreover, S-100 protein expression is well known in lacuna cells and some neoplastic myoepithelial cells in salivary pleomorphic adenoma, which is derived from epithelial origin. ${ }^{16}$ Coexpressions of sox9 and S-100 protein in matrix-producing carcinoma of the breast were biologically associated with transdifferentiation of neoplastic epithelial cells to chondrocytic cells.

In all of the current cases, aggrecan and type II collagen, which are specifically expressed in normal cartilage,,$^{3,4}$ were particularly deposited in the myxochondroid stroma; aggrecan deposition was 

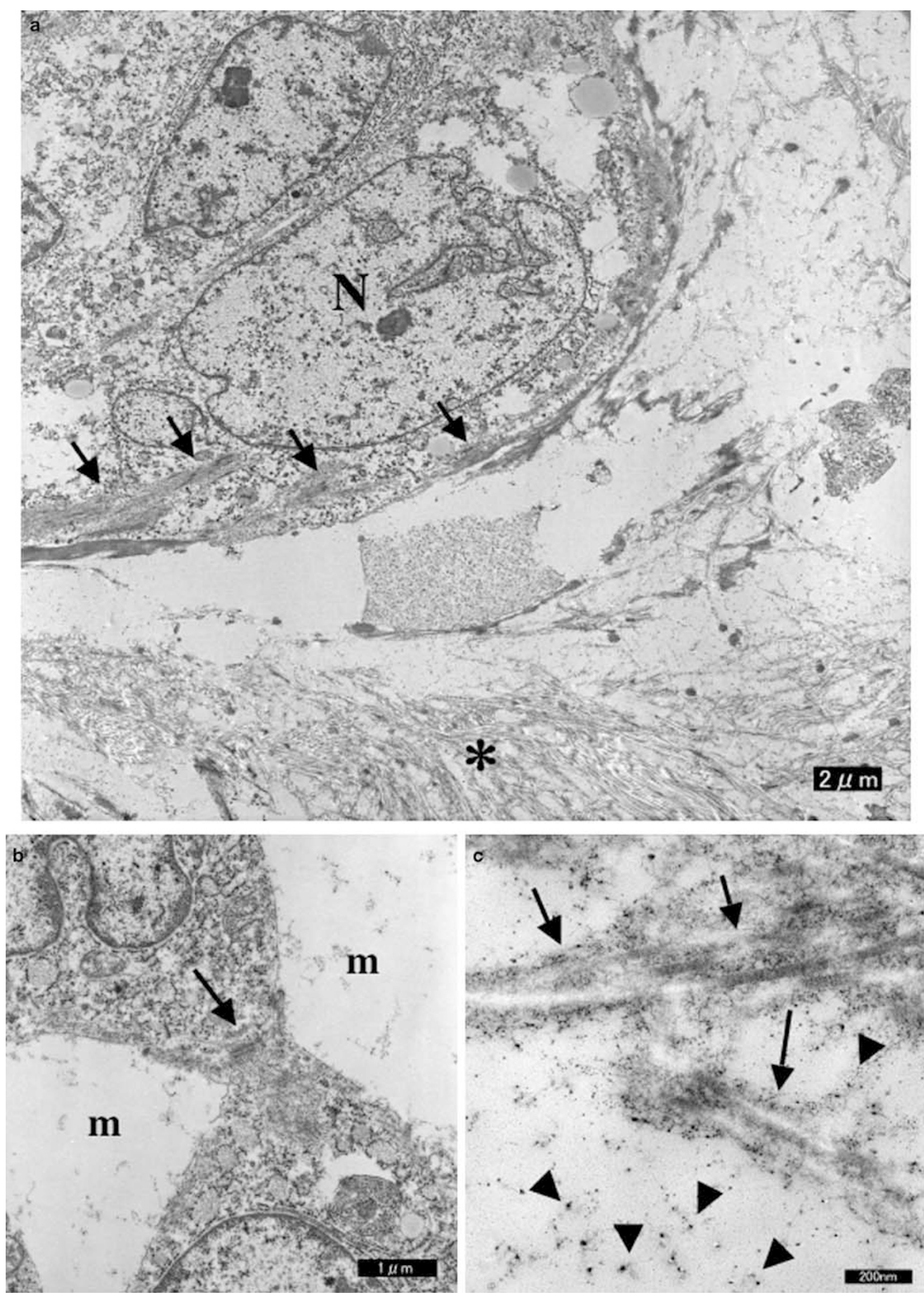
Figure 6 Ultrastructural findings. (a) The cuboidal cancer cells contained actin filaments (arrows) with immature dense patches at the periphery of the cells ( $\mathrm{N}$, nucleus). Within the matrix area adjacent to cancer cells, abundant collagen fibers (asterisks) with regular electron-dense bands were easily observed (case 2). (b) The desmosome-like intercellular junction structure (arrows) was seen between metaplastic cells, which have loose contact. m, matrix that contained electron-lucent materials (case 3). (c) The abundant collagen fibers (arrows), fine proteoglycan fibrils and cores (arrowheads), and homogeneous electron-lucent materials were easily observed in the oligocellular regions (case 2).

diffusely found in the matrix of matrix-producing carcinoma. In the current cases, the ultrastructural observation also indicated that the matrix of matrixproducing carcinoma composed of abundant collagen fibers and numerous proteoglycan fibrils and cores. Aggrecan deposition was also seen in myxoid and chondroid stroma of salivary pleomorphic adenomas, whereas type II collagen deposition was observed in only chondroid stroma of pleomorphic adenomas. ${ }^{5,6,22}$ Histochemically, toluidine blue stain also showed marked metachromasia of the stroma. The matrix nature of matrix-producing carcinoma of the breast was similar to that of salivary pleomorphic adenomas and normal cartilage. Type II collagen deposition in matrix-producing carcinoma was limited to lacunar formation regions. Although ChM-I is also a cartilage-specific noncollagenous matrix molecule, ${ }^{7,8}$ this molecule was weakly and focally deposited in the matrix of matrix-producing carcinoma. Such findings suggested that the matrix of matrix-producing carcinoma of the breast was similar to that of normal cartilage, but had not matured to that of the hypertrophic zone of growth plate cartilages. ${ }^{4}$ As sox9 induces aggrecan and type II collagen, such a cascade may exist in matrix-producing carcinoma of the breast. It remains unclear why, although myxochondroid tissue was seen, the cartilage-specific molecule ChM-I was expressed weakly.

Type I collagen deposition was also widely distributed in the matrix of our matrix-producing carcinoma cases. Type I collagen is the most common collagen in connective tissues and bones, ${ }^{23}$ but its deposition in matrix-producing carcinoma was much stronger than that in the surrounding breast tissues; therefore, cancer cells overexpressed type I collagen in matrix-producing carcinoma. Mature osseous tissues were not seen in the current cases, and marked deposition of type I collagen did not play a role in osteoblastic differentiation of cancer cells. As the significance of type I collagen deposition in matrix-producing carcinoma remains unclear, its overexpression in metaplastic cells may be related to the matrix formation of mammary matrix-producing carcinoma.

Type IV collagen deposition was observed around carcinomatous cell nests and metaplastic cells. Type IV collagen is a major basement membrane molecule, and this molecule was usually deposited between epithelial and mesenchymal cells. ${ }^{24}$ As massive deposition of type IV collagen was reported in salivary adenoid cystic carcinoma and pleomorphic adenoma, such an aberrant expression was associated with neoplastic myoepithelial cells. ${ }^{25,26}$ It is possible that metaplastic cells play a role in the overexpression of type IV collagen in matrix-producing carcinoma of the breast. From such findings, the roles of metaplastic cells in mammary matrix-producing carcinoma were similar to those of neoplastic myoepithelial cells in salivary pleomorphic adenomas. ${ }^{26}$

In conclusion, we examined four cases of matrixproducing carcinoma of the breast, histochemically and immunohistochemically, and the matrices of matrix-producing carcinoma were similar to those of normal fibrous cartilage from the immunohistochemical findings of type II and type I collagens, aggrecan, and ChM-I depositions. Aberrant expression of sox9 in metaplastic cells induces such cartilage-specific matrix molecules. Further examinations of the matrices of matrix-producing carcinoma are needed.

\section{Acknowledgements}

We thank Yoichi Watanabe, Oono Sachiyo, Kaori Nagata, Hiroshi Tashiro, Masatake Honda, Masato Abe, Mihoko Shimura, Chiho Sugiyama, Takuya Kawasaki, Kazue Shinnou, and Yukiko Fukasawa, who are the staff of the Pathology Division, Shizuoka Cancer Center Hospital, Shizuoka, Japan, for excellent technical assistance. We are grateful to Minako Ishii, who is the secretariat of Pathology Division, Shizuoka Cancer Center Hospital, Shizuoka, Japan.

\section{Disclosure}

We have no conflicting interests to declare.

\section{References}

1 Ellis IO, Schnitt SJ, Sastre-Garau X, et al. Invasive breast carcinoma: metaplastic carcinoma. In: Tvassolli FA, Devilee P (eds). Pathology and Genetics: Tumours of the Breast and Female Genital Organs. IARC Press: Lyon, France, 2003, pp 37-41.

2 Wargotz ES, Norris HJ. Metaplastic carcinomas of the breast. I. Matrix-producing carcinoma. Hum Pathol 1988;20:623-635.

3 Luo W, Guo C, Zhang J, et al. Aggrecan from start to finish. J Bone Miner Metab 2000;18:51-56.

4 Kusafuka K, Hiraki Y, Shukunami C, et al. Cartilagespecific matrix protein, chondromodulin-I (ChM-I), is a strong angio-inhibitor in endochondral ossification of human neonatal vertebral tissue in vivo: relationship 
with angiogenic factors in the cartilage. Acta Histochem 2002;104:167-175.

5 Zhao M, Takata T, Orawa I, et al. Immunohistochemical evaluation of the small and large proteoglycans in pleomorphic adenoma of the salivary glands. J Oral Pathol Med 1999;28:37-42.

6 Kusafuka K, Hiraki Y, Shukunami C, et al. Cartilagespecific matrix protein chondromodulin-I is associated with chondroid formation in salivary pleomorphic adenomas: immunohistochemical analysis. Am J Pathol 2001;158:1465-1472.

7 Hiraki Y, Tanaka H, Inoue H, et al. Molecular cloning of a new class of cartilage-specific matrix, chondromodulin-I, which stimulates growth of cultured chondrocytes. Biochem Biophys Res Commun 1991;175: 971-977.

8 Hiraki Y, Mutsui K, Endo N, et al. Molecular cloning of human chondromodulin-I, a cartilage-derived growth modulating factor, and its expression in Chinese hamster ovary cells. Eur J Biochem 1999; 260:869-878.

$9 \mathrm{Ng}$ LJ, Wheatley S, Muscat GEO, et al. Sox9 binds DNA, activates transcription, and coexpression with type II collagen during chondrogenesis in the mouse. Dev Biol 1997;183:108-121.

10 Lefebvre V, Huang W, Harley VR, et al. Sox9 is a potent activator of the chondrocyte-specific enhancer of the proá1(II) collagen gene. Mol Cell Biol 1997;17: 2336-2346.

$11 \mathrm{Bi}$ W, Deng JM, Zhang Z, et al. Sox9 is required for cartilage formation. Nat Genet 1999;22:85-89.

12 Wehrli BM, Haung W, De Crombrugghe B, Ayala AG, Czerniak B. 'Sox9', a master regulator of chodrogenesis, distinguishes mesenchymal chondrosarcoma from other small blue round cell tumors. Hum Pathol 2003;34:263-269.

13 Allen AC. So-called mixed tumors of the mammary gland of dog and man, with special reference to the general problem of cartilage and bone formation. Arch Pathol Lab Med 1940;29:589-624.

14 Murad TM, von Hamm E. Ultrastructure of myoepithelial cells in human mammary gland tumors. Cancer 1968;21:1137-1149.
15 Meryem MK, Kleer CG. p63 expression in breast cancer: a highly sensitive and specific marker of metaplastic carcinoma. Am J Surg Pathol 2004;28:1506-1512.

16 Morinaga S, Nakajima T, Shimosato Y. Normal and neoplastic myoepithelial cells in salivary glands: an immunohistochemical study. Hum Pathol 1987;8: 1218-1226.

17 Weber A, Langhanki L, Schutz A, et al. Expression profile of p53, p63, and p73 in benign salivary gland tumors. Virchows Archiv 2002;441:428-436.

18 Milanezi F, Pereira EM, Ferreira FV, et al. CD99/MIC2 surface protein expression in breast carcinomas. Histopathology 2001;39:578-583.

$19 \mathrm{Kim}$ JH, Do HJ, Yang HM, et al. Overexpression of SOX9 in mouse embryonic stem cells directs the immediate chondrogenic commitment. Exp Mol Med 2005;31:261-268.

20 Kolettas E, Muir HI, Barrett JC, et al. Chondrocyte phenotype and cell survival are regulated by cultured conditions and by specific cytokines through the expression of Sox-9 transcription factor. Rheumatology 2001;40:1146-1156.

21 Weiss AP, Dofman HD. S-100 protein in human cartilage lesion. J Bone Joint Surg Am 1986;68: 521-526.

22 Landini G. Immunohistochemical demonstration of type II collagen in the chondroid tissue of pleomorphic adenomas of the salivary glands. Acta Pathol Jpn 1991;41:270-276.

23 Linsenmayer TF. Collagens. In: Hay ED (ed). Cell Biology of Extracellular Matrix, 2nd edn. Plenum: New York, 1991, pp 7-44.

24 Visscher DW, Sarkar FH, Sakr W, et al. Immunohistologic analysis of invasive phenotype in breast carcinoma. A clinicopathologic study. Pathol Res Pract 1993;189:867-872.

25 Cheng J, Saku T, Okabe H, et al. Basement membranes in adenoid cystic carcinoma. An immunohistochemical study. Cancer 1992;69:2631-2640.

26 Saku T, Cheng J, Okabe H, et al. Immunolocalization of basement membrane molecules in the stroma of salivary pleomorphic adenoma. J Oral Pathol Med 1990;19:208-214. 